\title{
Sintesis Dan Karakterisasi Titanium Dioksida (Tio2) Plat Kaca Serta Aplikasi Pada Proses Fotodegradasi Metilena Biru
}

\section{Ni Putu Gita Anggreani , Rosyid ridho, Rika Endara Safitri}

Program Studi Kimia, Fakultas Matematika dan Ilmu Pengetahuan Alam Universitas PGRI Banyuwangi

Email korespondensi*: Rosyidridho@gmail.com

September 2019

\section{ABSTRAK}

Telah dilakukan pembuatan $\mathrm{TiO}_{2}$ Plat Kaca untuk fotokatalis yang digunakan dalam proses fotodegradasi zat warna metilena biru. Pada penelitian ini dilakukan pembuatan teknologi fotoadsorp dengan skala besar untuk proses penanganan limbah dalam jumlah besar. Teknologi fotoadsorp adalah modifikasi alat sederhana dengan menambahkan lampu UV sebanyak 8 unit untuk proses penyinaran dan dilakukan pengadukkan yang dimana pada pengaduknya dipasang $\mathrm{TiO}_{2}$ Plat Kaca. Pembuatan $\mathrm{TiO}_{2}$ Plat Kaca dilakukan dengan melapisi $\mathrm{TiO}_{2}$ yang mengandung etanol pada plat kaca. Pelapisan dilakukan dengan variasi $\mathrm{TiO}_{2}$ Plat Kaca 2, 4, 6, 8, dan 10x. Kemudian struktur kristal $\mathrm{TiO}_{2}$ Plat Kaca dianalisis menggunakan difraktometer sinar-X (XRD) dan didapatkan hasil terbaik pada pelapisan 8x. Pengujian keefektifitasan $\mathrm{TiO}_{2}$ Plat Kaca dilakukan dengan menentukan waktu penyinaran (1, 2, 3, 4, 5 dan 6 jam) dan banyak lampu (2, 4, 6 dan 8 unit) maksimum yang diaplikasikan pada zat warna metilena biru 5 ppm dan didapatkan hasil maxmimum pada waktu penyinaran 6 jam dan banyak lampu 8 unit. Setelah ditentukan waktu penyinaran dan banyak lampu optimum, kemudian dilakukan variasi pelapisan optimum. Larutan sampel diuji menggunakan Spektrofotometer Uv-Vis dengan panjang gelombang $663 \mathrm{~nm}$. Kemudian didapatkan variasi pelapisan maximum sebesar 10 kali pelapisan.

Kata Kunci : Metilena Biru, $\mathrm{TiO}_{2}$ Plat Kaca, Fotodegradasi

\section{PENDAHULUAN}

Pencemaran lingkungan yang disebabkan oleh zat pewarna, saat ini mulai cukup memprihatinkan, sehingga perlu adanya penanganan untuk mengatasi masalah tersebut. Banyaknya upaya penanganan secara konvensional seperti adsorpsi menggunakan zeolit atau karbon aktif namun terkadang hasilnya kurang efektif. Limbah zat warna merupakan senyawa organik yang terurai, bersifat resinten dan toksik. Salah satu zat warna yang sering digunakan dalam industri tekstil adalah metilen blue yang merupakan senyawa aromatik heterosiklik katonik. 
Senyawa metilena biru mempunyai struktur benzena yang sulit untuk diuraikan, bersifat toksik, karsinogenik dan mutagenik (Ljubas, 2010). Selain itu, banyaknya molekul zat warna dalam air akan menganggu proses fotosintesis (Batista et all., 2010). Dalam industri tekstil metilena biru merupakan zat warna yang sering digunakan, karena harganya ekonomis dan mudah diperoleh. Zat warna metilen blue merupakan zat warna dasar yang penting dalam pewarna kulit, kain mori, kain katun dan tannin. Penggunaan metilena biru dapat menimbulkan beberapa efek, seperti iritasi saluran pencernaan jika tertelan, menimbulkan sianosis jika terhirup dan iritasi pada kulit jika tersentuh (Hamdaoui dan chiha, 2006). Metode penanganan limbah zat warna untuk memenuhi baku mutu pencemaran yang relatif murah dan mudah diterapkan adalah metode fotodegradasi menggunakan fotokatalis Titanium dioksida $\left(\mathrm{TiO}_{2}\right)$ (Utubira et all, 2006). Aktivitas fotokatalis Titanium dioksida $\left(\mathrm{TiO}_{2}\right)$ dapat ditingkatkan melalui pengembanan pada material pendukung,seperti adsorben (Andarini et all, 2012) (Ramadhana et all, 2013). Metode fotodegradasi dapat menguraikan limbah zat warna menjadi komponen-komponen sederhana melalui oksidasi fotokatalitik. Aktivitas fotokatalitik dari $\mathrm{TiO}_{2}$ dapat ditingkatkan dengan penambahan suatu dopan seperti dopan $\mathrm{N}$ dari urea yang akan menyebabakan fotokatalis lebih aktif bekerja pada daerah sinar tampak (Darzi, et all, 2012). Fotokatalis $\mathrm{TiO}_{2}$ menerima banyak perhatian besar karena stabil (Chrysicopoulou, 2008) dan aman bagi manusia (Maschiro, 2001).

Fotokatalis biasanya dibagi menjadi dua jenis yaitu mobile dan imobile (tetap) (Li zhang, 2000). Fotokatalis mobile umumnya berbentuk serbuk, sedangkan untuk imobilisasi fotokatalis dapat dilakukan dengan berbagai cara. Fotokatalis Titanium dioksida $\left(\mathrm{TiO}_{2}\right)$ serbuk memiliki keuntungan dapat mendegradasi senyawa yang berbahaya dari limbah pewarna tekstil. Tetapi penggunaan $\mathrm{TiO}_{2}$ serbuk memiliki kelemahan dalam pengolahan limbah pewarna tekstil yaitu serbuk yang bersifat mobile (tetap) ini lebih cepat hilang dari larutan. Hal ini berakibat dalam mendegradasi limbah pewarna tekstil tidak efektif, karena membutuhkan jumlah yang banyak saat digunakan. Sedangkan jika $\mathrm{TiO}_{2}$ serbuk digunakan dalam jumlah banyak maka larutan menjadi keruh dan penyerapan cahaya pada proses degradasi akan menjadi kurang efektif. Pada fotokatalis imobile (bergerak) salah satu contohnya yaitu dengan pelapisan $\mathrm{TiO}_{2}$. Keuntungan dari Titanium dioksida $\left(\mathrm{TiO}_{2}\right)$ plat kaca yaitu tidak menganggu pada proses purifikasi (pemurnian sampel) dan $\mathrm{TiO}_{2}$ plat kaca ini dapat dipergunakan berulang kali. $\mathrm{TiO}_{2}$ plat kaca tidak menganggu radiasi cahaya, sehingga $\mathrm{TiO}_{2}$ dapat bekerja secara maksimal dengan bantuan sinar. 
Dalam penelitian ini digunakan $\mathrm{TiO}_{2}$ plat kaca sebagai fotodegradasi zat warna metilena biru menggunakan sumber sinar UV. Biasanya penelitian hanya dilaksanakan dalam skala kecil saja. Dari penelitian ini digunakan teknologi fotoadsorp dengan skala besar untuk proses penanganan limbah dalam jumlah besar. Teknologi fotoadsorp adalah modifikasi alat sederhana dengan menambahkan lampu UV sebanyak 8 unit untuk proses penyinaran dan dilakukan pengadukan yang dimana pada pengaduk dipasang $\mathrm{TiO}_{2}$ plat kaca dalam ukuran besar, guna untuk mengkatalis zat warna metilena biru yang akan menghasilkan oksidator untuk mendegradasi sejumlah limbah organik menjadi komponen-komponen yang sederhana dan tidak berdampak bagi lingkungan.

\section{METODE PENELITIAN}

\section{Alat dan Bahan Penelitian}

Alat yang dipergunakan dalam penelitian ini adalah seperangkat peralatan gelas laboratorium seperti gelas beaker, erlenmeyer, spatula, pengaduk, corong, labu ukur $500 \mathrm{~mL}$, kaca arloji, pipet ukur, mortar, penjepit, dan cawan petri. Satu set alat fotoadsorp yang terdiri dari 8 lampu uv 10 watt, pengaduk, kaca sampel, neraca analitik, spektrofotometri uv-vis (Shimadzu), oven (memmret), plat kaca ukuran 25,4 x 76,2 mm.

Bahan-bahan yang digunakan dalam penelitian ini adalah Titanium dioksida (e-merck), aquadest, metilena biru (pa), $\mathrm{H}_{3} \mathrm{PO}_{4} 76 \%$ (teknis), etanol 96\% (teknis), aseton, alumunium foil, kertas saring.

\section{Metodologi Penelitian}

Plat kaca ukuran 25,4 x 76,2 mm sebanyak 20 buah direndam dengan $\mathrm{H}_{3} \mathrm{PO}_{4} 76 \%$ selama 30 menit agar kerak pada kaca dapat hilang atau bersih, kemudian dibilas dengan aquadest, dan dibilas lagi dengan aseton guna menghilangkan aquadest yang masih tertempel pada plat kaca. Setelah itu plat kaca di oven pada suhu $45^{\circ} \mathrm{C}$ selama 1 jam. Sebanyak $5 \mathrm{~g}$ Titanium dioksida $\left(\mathrm{TiO}_{2}\right)$ ditambahkan etanol $96 \%$ sebanyak $50 \mathrm{~mL}$ sebagai pelarut.

Larutan $\mathrm{TiO}_{2}$ dilapiskan pada plat kaca dengan cara direndam dan digoyang-goyang selama 3 menit agar merata. Angkat plat kaca dan biarkan kering pada suhu ruang, setelah kering masukkan ke dalam oven dengan suhu $200^{\circ} \mathrm{C}$ selama 10 menit. Setelah di oven plat kaca di biarkan dingin kembali pada suhu ruang selama 15 menit. Proses pelapisan ini dilanjutkan dengan variasi pelapisan $\mathrm{TiO}_{2}$ sebanyak 2, 4, 6, 8 dan 10x pelapisan. Setelah selesai dilapisi 
sampel plat kaca di oven kembali pada suhu $200^{\circ} \mathrm{C}$ selama 3 jam. Kemudian sampel di analisis dengan X-RD.

\section{HASIL DAN PEMBAHASAN}

Karakterisasi XRD pada penelitian ini untuk mengetahui derajat kristalisasi dari lapisan tipis yang terbentuk pada $\mathrm{TiO}_{2}$ plat kaca. Pada penelitian ini dilakukan karakterisasi XRD dengan variasi pelapisan $\mathrm{TiO}_{2}$ plat kaca 2, 4, 6, 8, dan 10x. Variasi pelapisan $\mathrm{TiO}_{2}$ plat kaca ini dibandingkan dengan $\mathrm{TiO}_{2}$ standart digunakan sebagai acuan adanya lapisan $\mathrm{TiO}_{2}$ yang terbentuk pada plat kaca dan karakterisasinya sama dengan $\mathrm{TiO}_{2}$ standart. Data XRD $\mathrm{TiO}_{2}$ standart ditunjukkan pada gambar 4.1 di bawah ini:

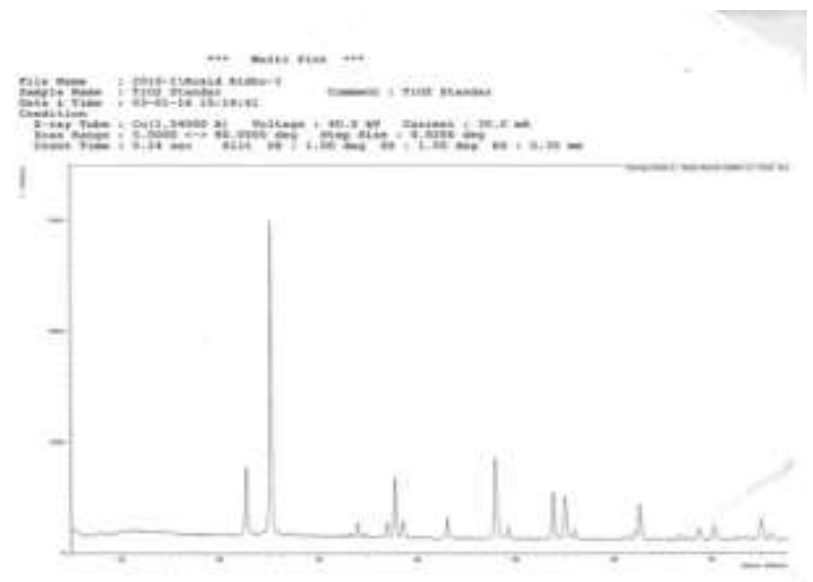

Gambar 4.1 XRD $\mathrm{TiO}_{2}$ standart

Dari data gambar di atas menunjukkan bahwa intensitas tertinggi pada $\mathrm{TiO}_{2}$ standart sebesar 2025 dengan sudut $2 \theta=25,2^{0}$ dan intensitas terendah dengan sudut $2 \theta=76^{0}$ sebesar 67 . Pada hasil pelapisan $\mathrm{TiO}_{2}$ plat kaca, yang memiliki kemiripan karakterisasi dengan $\mathrm{TiO}_{2}$ standart adalah pelapisan 8 kali. Data $\mathrm{TiO}_{2}$ plat kaca pelapisan $8 \mathrm{x}$ dapat dilihat pada gambar 4.2

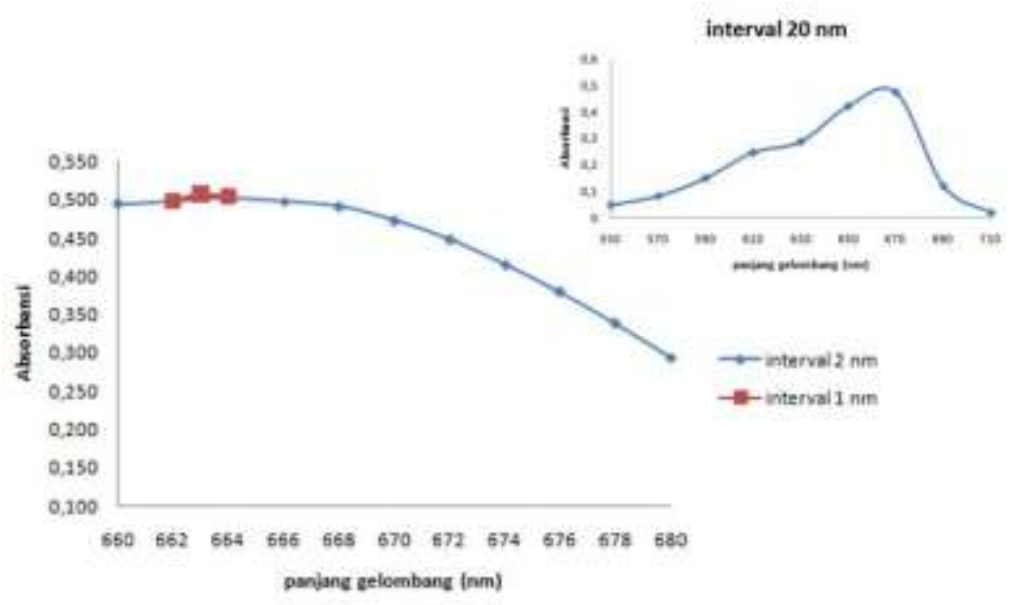

Gambar 4.2 XRD $\mathrm{TiO}_{2}$ plat kaca pelapisan $8 \mathrm{x}$

Dari hasil data di atas dapat disimpulkan bahwa adanya lapisan tipis yang terbentuk pada plat kaca, akan tetapi pada pelapisan 8x lebih baik dibandingkan pada 10x. Tujuan dari 
penggunaan XRD ini adalah untuk mengetahui $\mathrm{TiO}_{2}$ ini terbentuk pada strukutur anatase, rutil atau brookil. Dan anatase terbentuk pada suhu $120-500^{\circ}$ C.. Panjang gelombang maksimum diperoleh dari hubungan antara panjang gelombang dan absorbansi. Grafik ditunjukkan pada gambar 4.3 di bawah ini:

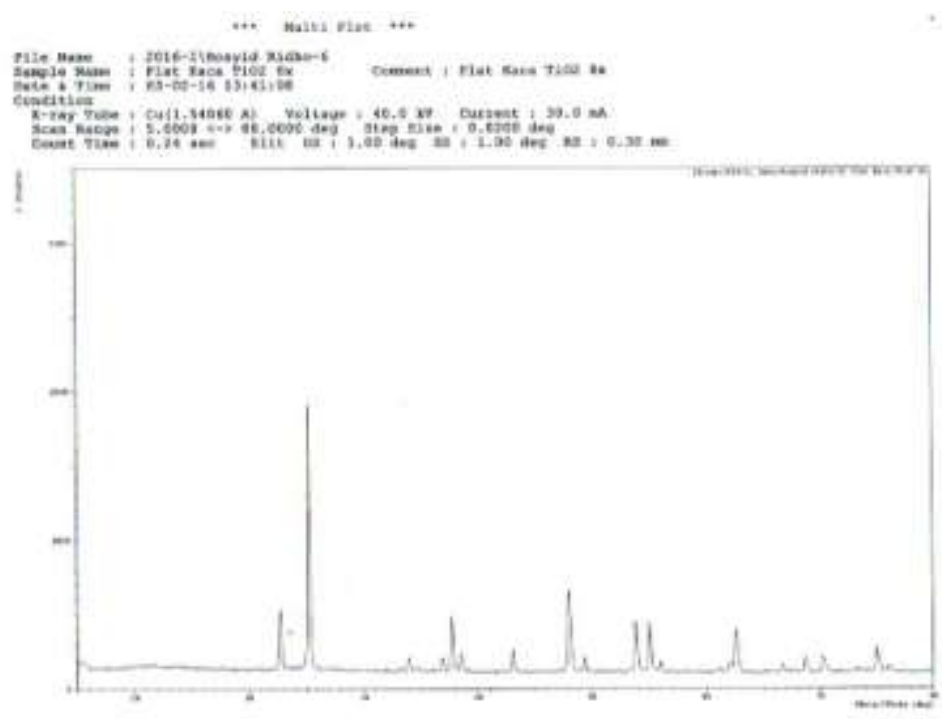

Gambar 4.3 Grafik Scanning Metilena Biru 2,5 ppm dengan panjang gelombang 550$710 \mathrm{~nm}$

Grafik di atas menunjukkan bahwa panjang gelombang maksimum dan larutan metilena biru 2,5 ppm adalah $663 \mathrm{~nm}$ dengan absorbansi 0,507 nm. Panjang gelombang maksimum dari larutan metilena biru yang diperoleh akan digunakan untuk absorbansi larutan metilena biru pada penelitian selanjutnya. Pada proses fotodegradasi metilena biru dilakukan dengan katalis $\mathrm{TiO}_{2}$ Plat Kaca dengan cara menyinari larutan metilena biru dan $\mathrm{TiO}_{2}$ Plat Kaca. Penyinaran dilakukan dengan menggunakan sinar UV dan pengaplikasian fotokatalis ini dilakukan dengan 2 tahap yaitu penentuan waktu penyinaran dan jumlah lampu optimum dan pelapisan $\mathrm{TiO}_{2}$ Plat kaca optimum. Penentuan waktu penyinaran dan lampu maksimum pada proses fotodegradasi metilena biru dengan katalis $\mathrm{TiO}_{2}$ Plat Kaca dilakukan dengan variasi waktu penyinaran selama 1, 2, 3, 4, 5, dan 6 jam dan variasi lampu sebanyak 2, 4, 6, dan 8 unit terhadap larutan metilena biru 5 ppm 
dan $\mathrm{TiO}_{2}$ Plat Kaca 6x pelapisan. Dari proses tersebut diperoleh hasil yang ditunjukkan pada grafik di bawah ini:

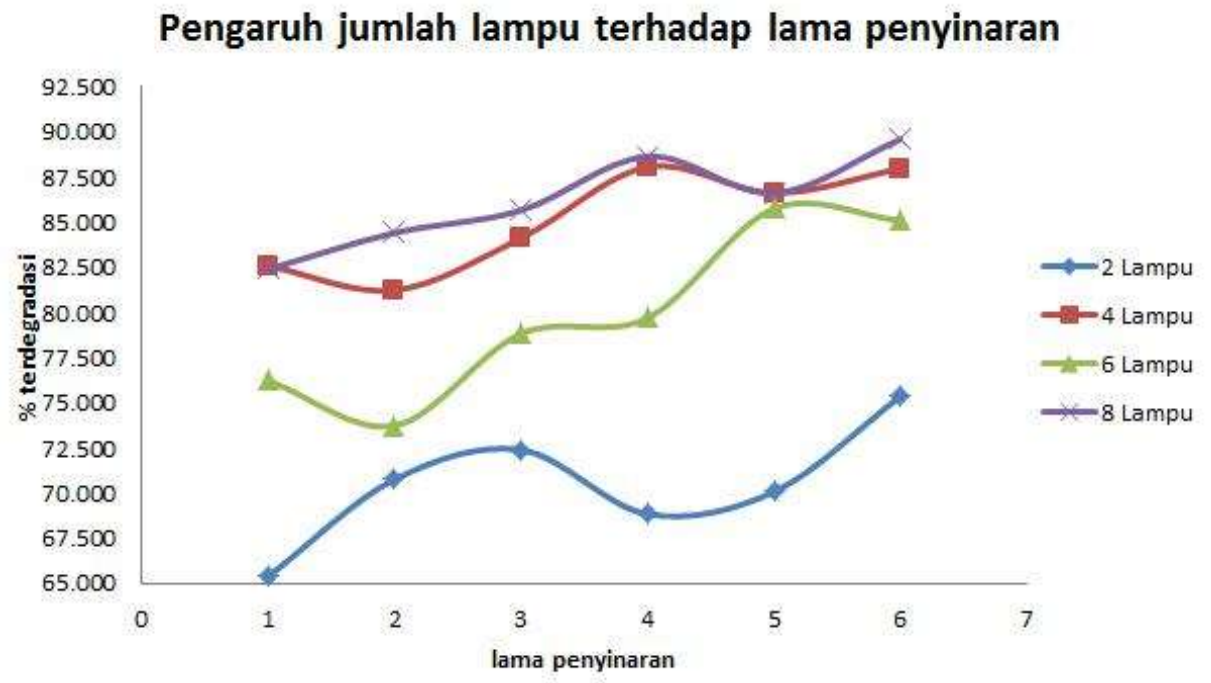

Gambar 4.5 Pengaruh jumlah lampu terhadap lama penyinaran pada larutan metilena Biru 5 ppm. Pada gambar 4.5 di atas dilakukan penyinaran menggunakan lampu UV sebanyak 2, 4, 6, dan 8 unit dengan variasi lama penyinaran 1, 2, 3, 4, 5 dan 6 jam. Banyaknya lampu dan lama penyinaran mempengaruhi proses fotodegradasi. Untuk mengetahui pengaruhnya dapat dihubungkan dengan presentase (\%) degradasi. Penelitian (Dony dkk., 2013) menunjukkan bahwa waktu penyinaran mempengaruhi \% degradasi zat warna metilena biru. Semakin lama waktu penyinaran maka \% degradasi semakin tinggi.

Penentuan pelapisan $\mathrm{TiO}_{2}$ Plat Kaca maximum pada proses fotodegradasi metilena biru dengan variasi katalis $\mathrm{TiO}_{2}$ Plat Kaca 2, 4, 6, 8, dan 10x pelapisan dilakukan dengan waktu penyinaran maksimum selama 6 jam dan banyak lampu UV optimum sebanyak 8 unit terhadap larutan metilena biru 5 ppm. Dari proses tersebut diperoleh hasil yang ditunjukkan pada grafik di bawah ini: 
gambar 4.6 variasi pelapisan $\mathrm{TiO}_{2}$ Plat Kaca pada larutan Metilena Biru 5 ppm

\subsubsection{Pengaruh Waktu Penyinaran dan Banyak Lampu Terhadap}

\section{Penggunan $\mathrm{TiO}_{2}$ Plat Kaca}

Pengaruh penggunakan $\mathrm{TiO}_{2}$ Plat Kaca terhadap waktu penyinaran dan banyaknya lampu UV bertujuan untuk mengetahui adanya pengaruh antara waktu penyinaran dan banyaknya lampu dalam mendegradasi sampel metilena biru menggunakan analisis varian (Anova) dua faktor. Data analisis Anova ditunjukkan pada Tabel 4.6 sebagai berikut:

Tabel 4.6 Perhitungan Anova

ANOVA

\begin{tabular}{lrrrrrr}
\hline $\begin{array}{l}\text { Source of } \\
\text { Variation }\end{array}$ & \multicolumn{1}{c}{ SS } & df & \multicolumn{1}{c}{ MS } & \multicolumn{1}{c}{$F$} & P-value & Fcrit \\
\hline Rows & 929,260 & 3 & 309,753 & 63,152 & $9,71 \mathrm{E}-09$ & 3,287 \\
Columns & 174,037 & 5 & 34,807 & 7,096 & 0,001375 & 2,901 \\
Error & 73,573 & 15 & 4,905 & & & \\
& & & & & & \\
Total & 1176,870 & 23 & & & & \\
\hline
\end{tabular}

Dari tabel 4.6 di atas menunjukkan bahwa dari kedua nilai $F$ hitung yaitu 63,152 dan 7,096 lebih besar dibandingkan dengan $\mathrm{F}$ tabel yaitu 3,287 dan 2,901. Hal ini menunjukkan bahwa ada pengaruh antara waktu penyinaran dan banyak lampu UV yang digunakan terhadap efektivitas fotodegradasi metilena biru.

\section{Kesimpulan Dan Saran}

\section{Kesimpulan}

Dari hasil penelitian dan pembahasan diatas maka dapat disimpulkan bahwa :

Semakin lama waktu penyinaran maka akan meningkatkan efektivitas fotodegradasi larutan Metilena Biru. Semakin banyak lampu Uv yang digunakan maka $\mathrm{OH}$ radikal yang dihasilkan akan bertambah juga, sehingga efektivitas \% fotodegradasi Metilena Biru semakin tinggi. Fotodegradasi larutan Metilena Biru 5 ppm dapat tercapai secara maksimum dengan waktu 
penyinaran selama 6 jam dan banyak lampu Uv 8 unit yaitu sebesar 89,615\%. Pelapisan $\mathrm{TiO}_{2}$ plat kaca dalam mendegradasi Metilena Biru didapatkan 10x pelapisan lebih efektif dengan \% terdegradasi $89,808 \%$.

\section{Saran}

Pada penelitian ini diharapkan untuk penelitian selanjutnya dapat memodifikasi $\mathrm{TiO}_{2}$ plat kaca agar tidak mudah rontok pada saat diaplikasikan. Serta dapat dilakukan uji SEM, guna mengetahui ikatan yang terjadi pada $\mathrm{TiO}_{2}$ dan Plat kaca.

\section{DAFTAR PUSTAKA}

Ali, R., \& Siew, O.B. 2010. Photodegradation New Methylene Blue in Aqueous Solution Using Zinc Oxide and Titanium Dioxide as Catalyst. Jurnal Teknologi University of Technology Malaysia. Malaysia.

Andarini, N.R., Wardhani, S., dan Khunur, M.M., 2012, Fotodegradasi Zat Warna Jingga Metil Menggunakan TiO2-Zeolit dengan Penambahan Anion Anorganik NO3-, Kimia.Student Journal, Vol. 1, No. 1, pp. 98-104, Universitas Brawijaya, Malang.

Anwar, D.I. 2011. Sintesis Komposit Fe-TiO2-SiO2 Sebagai Fotokatalis Pada Degradasi Erionyl Yellow. Tesis, FMIPA, Universitas Gadjah Mada, Yogyakarta.

Batista, A.P. L., Carvalho, H. W., Luz, G. H. P., Martins, P. F. Q., Goncalves, M., Oliveira, L. C. A. O. 2010. Preparation of $\mathrm{CuO} / \mathrm{SiO} 2$ and Photocatalytic Activity by Degradation of Methylene Blue. Environ Chem Lett, (8), 63-67.

Darajat, S., Aziz, H., dan Alif, A., 2008, Seng Oksida (ZnO) Sebagai Fotokatalis pada Proses Degradasi Senyawa Biru Metilen, J.Ris. Kim., Vol 1, No 2, pp. 179-186.

Darzi, S. J., Mahjoub, A. R., Sarfi, S., 2012, Visible-Light-Active Nitrogen Dopen TiO2 Nanoparticles Prepared by Sol-Gel Acid Catalyzed Reaction, Iranian Journal of Materials Science \& Engineering, Vol. 9(3): 17-23

Dony, N., Azis, H., Syukri. 2013. Study Fotodegradasi Biru Metilen di Bawah Sinar Matahari Oleh $\mathrm{ZnO} \mathrm{SnO}_{2}$ yang Dibuat Dengan Metoda Solid State Reaction. Prosiding Semirata FMIPA Universitas Lampung, 297-303. 
Hamdaoui, O. and Chiha, M., 2006, Removal of Methylene Blue from Aqueous Solutions by Wheat Bran, Acta Chim. $54: 407-418$

Khopkar, S.M., 1990, Konsep Dasar Kimia Analitik, UI Press, Jakarta.

Kuo W.S and P.H. Ho. 2001. Solar Photocatalytic Decolorization of Metilen biru in Water. J. Chemosphere, 45:77-83

Licciulli A., Lisi D. 2002. Self-Cleaning Glass. Universita Degli Studio Di Lecce

Ljubas, D., Curcovic, L., Dobrovic, S. 2010. Photocatalytic degradation of an Azo Dye by UVIrradiation at 254 and $365 \mathrm{~nm}$. Transactions of Famena XXXIV-1.

Masahiro Terashima, Narumi Inoue, Shigeru Kashiwabara, Ryiozo Fujimoto,Phtocatalytic $\mathrm{TiO}_{2}$ thin films deposited by pulsed laser ablation technique, Applied Surface Science 169-170(2001)535.

Radecka M., Rekas M, Trenczek-Zajac A, Zakrzewsk K. 2008. Importance of theband gap energi and flat band potential for application of modified TiO2photoanodes in water photolysis. J. Power Sources., Volume 181, 46-55

Ramadhana, A.K.K., Wardhani, S., dan Purwonugroho, D., 2013, Fotodegradasi Zat Warna Methyl Orange Menggunakan TiO2-Zeolit dengan Penambahan Ion Persulfat, Kimia.Student Journal, Vol. 1, No. 2, pp. 168-174, Universitas Brawijaya, Malang.

Tjahjanto, R.T dan J. Gunlazuardi. 2001. Preparasi Lapisan Tipis SebagaiFotokatalis: Keterkaitan antara Ketebalan dan Aktivitas Fotokatalisis.Makara. Jurnal Penelitian Universitas Indonesia, Vol 5, No 2: 81-91.

Underwood, A.L., and R.A. Day. 1980. Quantitative Analysis. 4thEdition. Prentice-Hall.Inc. Hal 393-395. 
Utubira, Y., Wijaya, K., Triyono, dan Sugiharto, E., 2006, Preparation and Characterization of TiO2-Zeolite and Its Application to Degrade Textille Wastewater by Photocatalytic Method, Indo. J. Chem., Vol 6 (3), pp. 231-237.

Yu, J.C., and L.Y.L. Chan.1998, Photocatalityc Degradation of a Gaseous organic Pollutant, Journal of Chemical Education, Vol. 75, No.6.

Zaleska, Adriana, 2008, Doped-TiO2: A Review, Recent Patents on Engineering,

Bentham Science Publishers Ltd, 2, 157-164

Zsolt, Pap. 2011. Synthesis, Morpho-structural Characterization andEnveronmental Aplication of Titania Photocatalysts Obtained by RapidCrystallization. Ph.D Dissertation. University of Szeged, Babes-BolyaiUniversity. Szaged, Hungary, Cluj-Napoca, Romania. 